\section{Outreach Program} Interdisciplinary Electron Microscopy Facility State University of New York, New Paltz, NY

B. L. Redmond, Director

Most outreach programs in microscopy are still in their embryonic stages of development. Indeed, from the correspondence I have received to date through my contact with MSA's MICRO, many are only in the gestation phase within the minds of one or two concerned and interested persons. Most outreach programs begin, as ours did, as "show and tell" demonstrations, and most industrial outreach programs adhere rather strictly to the "show and tell" format simply because they are not "in the business of education". While show and tell sessions certainly have their value (we also continue to conduct such sessions), this format does not address what we consider to be the real issue - educational reform. I have worked extensively with the Greater Newburgh School District in developing a program (based in large part on microscopy) that is designed to bring about educational change. This program, the essence of which is presented below, involves in-service training programs, curriculum development (K-12), summer science (microscopy) camps (for grades 5-8) and is being generously supported by AMRAY, Inc. The innovation and potential of this program has also been recognized by the State Education Department, which has granted the school district $\$ 79,000$ for continued development with special emphasis on grades 5-7.

This program, entering its third year, is designed to restructure science education K-12. No longer an industrial society whose populace requires only basic skills, we are now an informational society in which basic member skills must be augmented with higher-order thinking skills. The goals of education must reflect the needs generated by this change. Education must not only prepare individuals to function in a technological society but must nur- ture and foster creativity so that our nation can be technically and economically competitive in the global market. This program is a "working model" for producing the systemic changes that are needed in science education so that ALL students develop a full appreciation of science as a basic subject necessary to and prerequisite for literacy in a technological society.

Our model is a simulated R\&D facility that locates the university science professor and the industrial engineer or scientist as "Scientist-in-Residence" in the schools where they interact with teachers and students to bring their expertise directly into the classroom. They serve as role models and convey the excitement related to their disciplines of science, mathematics, engineering and technology. The way that teaching and learning takes place is changed. Traditionally, the roles of students and teachers have been that of passive information receivers and givers. In our model students and teachers are active researchers who, together, think critically, acquire and use knowledge and creative problem solving skills, and apply science and technology to solve real-life, complex, multistep problems.

Students are turned into active learners by exploring technology at three operational levels: inputting, processing and outputting. Technology is used to extend observation senses and to share information. These technologizes include: opttical microscopy (simple hand lenses through advanced techniques), computer-based scanning electron microscopy with digital imaging, scanning tunnelling microscopy, telecommunications and computer-aided instruction.

A series of creative and innovative research projects involving both students and teachers as researchers not only links the various technologies, but encourages students to develop new applications of science, i.e. new technologies. Thus, previously isolated facts, traditionally from separate courses, now become integrated, meaningful, learning experiences through explorations.

This program is being developed concurrently by Dr. Annette Saturnelli, Director of Science, Greater Newburgh School District (Tel:: 914-563-7462) and myself (Tel.: 914-257-3774, Fax: 914-257-3791). Persons interested in the particulars of this working model are invited to contact either of us.
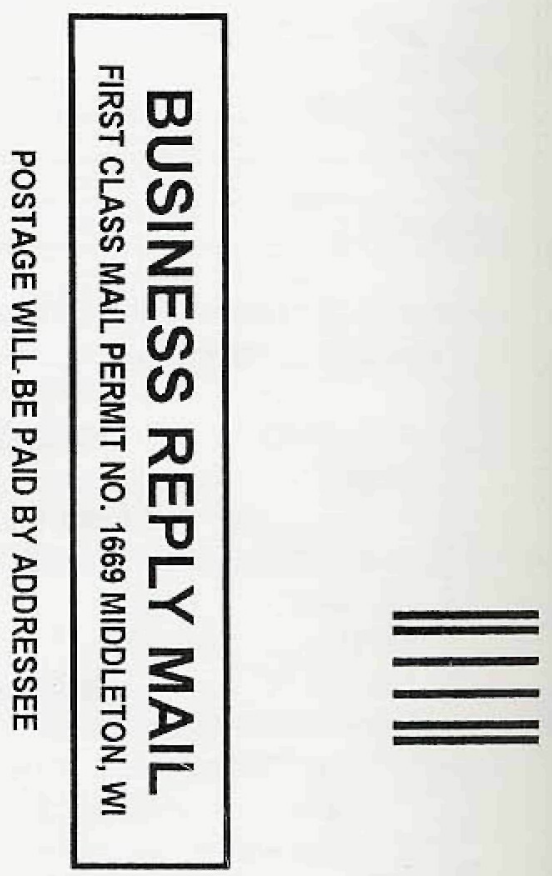